\title{
Impact of a Reduced Arctic Sea Ice Cover on Ocean and Atmospheric Properties
}

\author{
Jan Sedláček, Reto Knutti, Olivia Martius,* and Urs Beyerle \\ Institute for Atmospheric and Climate Science, ETH Zürich, Zurich, Switzerland
}

(Manuscript received 21 June 2010, in final form 1 June 2011)

\begin{abstract}
The Arctic sea ice cover declined over the last few decades and reached a record minimum in 2007, with a slight recovery thereafter. Inspired by this the authors investigate the response of atmospheric and oceanic properties to a 1-yr period of reduced sea ice cover. Two ensembles of equilibrium and transient simulations are produced with the Community Climate System Model. A sea ice change is induced through an albedo change of $1 \mathrm{yr}$. The sea ice area and thickness recover in both ensembles after 3 and $5 \mathrm{yr}$, respectively. The sea ice anomaly leads to changes in ocean temperature and salinity to a depth of about $200 \mathrm{~m}$ in the Arctic Basin. Further, the salinity and temperature changes in the surface layer trigger a "Great Salinity Anomaly" in the North Atlantic that takes roughly 8 yr to travel across the North Atlantic back to high latitudes. In the atmosphere the changes induced by the sea ice anomaly do not last as long as in the ocean. The response in the transient and equilibrium simulations, while similar overall, differs in specific regional and temporal details. The surface air temperature increases over the Arctic Basin and the anomaly extends through the whole atmospheric column, changing the geopotential height fields and thus the storm tracks. The patterns of warming and thus the position of the geopotential height changes vary in the two ensembles. While the equilibrium simulation shifts the storm tracks to the south over the eastern North Atlantic and Europe, the transient simulation shifts the storm tracks south over the western North Atlantic and North America. The authors propose that the overall reduction in sea ice cover is important for producing ocean anomalies; however, for atmospheric anomalies the regional location of the sea ice anomalies is more important.

While observed trends in Arctic sea ice are large and exceed those simulated by comprehensive climate models, there is little evidence based on this particular model that the seasonal loss of sea ice (e.g., as occurred in 2007) would constitute a threshold after which the Arctic would exhibit nonlinear, irreversible, or strongly accelerated sea ice loss. Caution should be exerted when extrapolating short-term trends to future sea ice behavior.
\end{abstract}

\section{Introduction}

The Arctic sea ice area and thickness have been decreasing steadily over the last few decades (Maslanik et al. 2007; Nghiem et al. 2007; Serreze et al. 2007; Comiso et al. 2008). Serreze et al. (2007) reported that the decrease occurred throughout the year. However, the summer months experienced a larger decrease than the winter months. During summer 2007 the Arctic sea ice area was reduced substantially. The minimum sea ice area in

\footnotetext{
* Current affiliation: Oeschger Center for Climate Change Research, University of Berne, Berne, Switzerland.

Corresponding author address: Jan Sedláček, Institute for Atmospheric and Climate Science, ETH Zürich, Universitätstrasse 16, 8092 Zurich, Switzerland.

E-mail: jan.sedlacek@env.ethz.ch
}

September was $28 \%$ lower than the previous record low in 2005 and $38 \%$ lower than the climatological average (Comiso et al. 2008). While the thickness decrease for summer 2007 was close to the linear trend observed over the last few decades, the area reduction was much larger than expected from the linear trend (Lindsay et al. 2009). During the years following the minimum of 2007 the sea ice area remained low but started to increase again [National Snow and Ice Data Center (NSIDC); http:// nsidc.org/]. The sea ice thickness, on the other hand, continued to decrease (Giles et al. 2008; Kwok et al. 2009). These trends in sea ice are underestimated by the atmosphere-ocean general circulation models used for the Intergovernmental Panel on Climate Change (IPCC) Fourth Assessment Report (AR4) (Solomon et al. 2007; Stroeve et al. 2007; Boé et al. 2009).

During the summer of 2007 an unusually persistent high pressure system over the Beaufort Sea favored

DOI: 10.1175/2011JCLI3904.1

(C) 2012 American Meteorological Society 
strong winds and increased heat advection into the Arctic. Associated with this high pressure system the skies were predominantly clear (see, e.g., Overland et al. 2008; Stroeve et al. 2008). While many scientists agree that both natural variability and anthropogenic forcing contributed to the observed large sea ice loss during summer 2007 (Overland et al. 2008), the question arises whether this could be the precursor to large sea ice loss events such as those modeled by Holland et al. (2006).

Several studies have tried to shed some light into which process was dominant in producing the low-sea ice area during 2007. Lindsay et al. (2009) argue that the stronger winds were one of the main players but only together with a steadily declining sea ice thickness. Model results with thicker ice and 2007 wind forcing did not produce a reduction in sea ice. Kauker et al. (2009), with an adjoint model, found that the thickness during March and wind stress during May and June were partly responsible for determining the reduction and that the $2-\mathrm{m}$ temperature during September was the direct key player. The observed clear sky and thus the increased downwelling shortwave radiation did not contribute to the reduction of the sea ice cover because the increased shortwave radiation and the reduced sea ice cover were located in different regions. More likely the observed increased cloudiness north of Siberia increased the downwelling longwave radiation, which enhanced the melt (Schweiger et al. 2008). Contradicting Schweiger et al.'s results, Kay and Gettelman (2009) note that the largest melt occurred between June and July. During that time the cloud cover was low and thus enhanced the ice-albedo feedback. In a regional model, Zhang et al. (2008) used September 2007 as the initial condition and produced an ensemble sea ice forecast for 2008 with forcing fields derived from National Centers for Environmental PredictionNational Center for Atmospheric Research (NCEPNCAR) data (Kalnay et al. 1996) from 2000 to 2007. They showed that the sea ice thins but no large area reduction occurred. One drawback from the abovementioned studies is that they use prescribed atmospheric forcings and thus do not allow feedbacks between the atmosphere-ice-ocean-land system.

In the present study we change the point of view and study the impact of a sea ice anomaly, such as during 2007, on atmospheric and oceanic properties. In contrast to earlier work, all components are fully interactive and only the sea ice albedo is perturbed. We answer the following questions: what are the differences between equilibrium and transient behavior? How long can an anomaly be detected in the sea ice, ocean, and atmosphere after an initial sea ice anomaly? What mechanisms transport the anomaly signal from the Arctic Basin to other locations? Note that we are not trying to reproduce the exact response to the observed 2007 sea ice decline, but rather investigate the response to a reduction of sea ice cover of $1 \mathrm{yr}$. Thus, a comparison with observations should be made with care.

Several authors have investigated changes in atmospheric properties due to long-term sea ice loss. The changes observed in the Arctic are believed to arise not only directly from changes in atmospheric and oceanic properties; feedbacks also play an important role (Overland and Wang 2010). A reduction of sea ice extent is accompanied by deeper and stronger cyclones over the Arctic, while the cyclone frequency remains almost unchanged (Simmonds and Keay 2009). However, the influence of the sea ice concentration on the cyclonic activity and wind fields is unclear (e.g., Simmonds and Keay 2009; Overland and Wang 2010). Liu et al. (2009) investigated the effects of clouds, sea ice concentration, and residual forcings (such as heat content changes and heat advection) on surface air temperature (SAT) in different regions of the Arctic. Not surprisingly, the influence of sea ice concentration is largest over areas of large ice changes and small over the pack ice and ocean. Generally, during winter and summer the clouds tend to be a more dominant forcing than the sea ice concentration. During rapid sea ice loss events the cloud cover is reduced during summer and increased during autumn (Vavrus et al. 2010). The changes arise mainly from low-level clouds. Vavrus et al. (2010) note that the cloud cover should increase with decreasing ice cover. However, there is no evidence that sea ice is leading the cloud cover or vice versa. Strey et al. (2010) used a weather forecast model to investigate the changes in the atmosphere caused by a reduction of sea ice. They found that the local response is thermodynamic while the remote response is likely advective or dynamical.

Other possible dynamical and thermodynamic responses in the atmosphere might include a triggering of stationary Rossby wave trains producing lower temperatures over Eurasia (Honda et al. 2009), compensation of higher pressures over the Arctic with lower pressures over midlatitudes and increased precipitation north of $40^{\circ} \mathrm{N}$ (Francis et al. 2009), and changes in geopotential height over some parts of the Arctic region (e.g., Bhatt et al. 2008; Overland and Wang 2010).

Våge et al. (2009) measured the start of oceanic deep convection near southern Greenland during winter $2007 / 08$ after a few years of absence. They claim that it might be a consequence of changes in the tip jet over southern Greenland. They do not link this phenomenon to a reduction of sea ice but more to La Niña conditions that were in place then and to increased sea ice in the Labrador Sea.

The remainder of the paper is structured as follows: in section 2 we present the model used and the experimental 
setup. In section 3 the results are presented and in section 4 we summarize our findings and discuss their implications.

\section{Model and experimental setup}

This study is conducted with the Community Climate System Model, version 3.5 (CCSM3.5). The model is based on CCSM3 (Collins et al. 2006) but includes several changes (Gent et al. 2010). According to Gent et al. (2010), the CCSM3.5 shows an improved representation of tropical variability, the excessive amount of low-level clouds in the Arctic is reduced, the ridging of sea ice and the representation of snow on top of ice is also improved, and the radiative scheme of the ice component is changed. The ocean component includes modifications in the horizontal viscosity, the vertical mixing, and the eddy parameterization. Further, several parts of the hydrological cycle have been modified in CCSM3.5, as well as representations of plants and canopies. This list is by no means complete.

For the atmosphere and land components we use the finite volume $1.9^{\circ} \times 2.5^{\circ}$ resolution, and for the ocean and ice components the horizontal resolution is $1^{\circ}$ on a nonuniform rotated grid in which the North Pole is placed over Greenland. In the vertical the atmosphere has 26 hybrid layers and the ocean includes 40 unequally spaced layers. This setup is situated between the standard resolutions of T42 and T85, and is a compromise between data storage, computing time, and the benefits of relatively high resolution. For example, the CCSM3 produces too thick sea ice in the eastern Siberian Sea; however, increasing the resolution reduces this bias (DeWeaver and Bitz 2006). The global SAT drift in the equilibrium run is smaller than $0.01^{\circ} \mathrm{C}(100 \mathrm{yr})^{-1}$.

For this study we use two different simulation setups. First, we let the model run to equilibrium with a $\mathrm{CO}_{2}$ concentration of $355 \mathrm{ppm}$. This value corresponds to the $1990 \mathrm{CO}_{2}$ concentration (hereafter EQUIL). From this equilibrium we branch eight different ensembles at different times after the system reached a steady state. In the first year of the branched runs we reduce the snow (on ice) and ice albedo values from 1 January to 31 December to the values described below (EQUIL-ANOM).

Holland et al. (2006) observed periods of rapid ice loss in transient simulations. Thus, in a second set of simulations we simulate a transient climate (TRANS) to investigate if the response to a large reduction could be a trigger for such rapid ice loss events. The runs start from identical initial conditions except for the $\mathrm{CO}_{2}$ values, which are set to $250,260,270$, and $280 \mathrm{ppm}$, respectively. This can be thought of as perturbing the initial condition of a set of ensembles. The $\mathrm{CO}_{2}$ concentration is then increased by
$1 \% \mathrm{yr}^{-1}$. When the $\mathrm{CO}_{2}$ concentration of these four runs reaches a value of about $400 \mathrm{ppm}$, we branch four runs with reduced albedo as in the EQUIL-ANOM. The same is done when the four runs reach about $450 \mathrm{ppm}$, giving a total of eight ensembles (TRANS-ANOM hereafter). The branch occurs between years 40 and 60 of the TRANS runs depending on the initial $\mathrm{CO}_{2}$ concentration.

The albedo anomaly is created by reducing the albedo values of visible snow (on ice) and ice by 0.12 and 0.18 to 0.86 and 0.57 , respectively. The albedo in the infrared band is reduced by 0.08 to 0.65 for snow and by 0.09 to 0.36 for ice. This reduction is not meant to correspond to any physical process but rather is a physically consistent way to introduce a perturbation. Other options (e.g., setting the ice thickness to zero) in some regions are possible but are more likely to result in inconsistencies between the state of the ocean, atmosphere, and ice. The perturbations are $50 \%$ larger than those used by Bitz et al. (2006) to create an ice reduction corresponding to that of doubling the $\mathrm{CO}_{2}$ concentration.

We note that eight ensemble members are not enough to cover the whole range of variability. However, the range can give some indication of the variability that can be expected. Furthermore, because of the setup of the experiments we expect a too large input of freshwater into the Arctic Ocean due to the melting of sea ice. Thus, some caution has to be applied when comparing the results to observations.

As mentioned in the introduction the wind forcing was also a dominant factor during 2007. Thus, we also tried to produce a sea ice area anomaly by increasing the wind stress forcing over sea ice. While in the central Arctic the sea ice area decreased, the sea ice was exported to the Barents Sea (not shown). The hemispheric sea ice area and thickness remained almost unchanged. Thus, we left this option aside.

\section{Results}

\section{a. Sea ice}

As shown in Fig. 1 the CCSM3.5 equilibrium sea ice thickness during March and September shows good agreement with climatology (e.g., Bourke and Garrett 1987; Laxon et al. 2003). The thicknesses north of Greenland and around the Canadian Arctic archipelago (CAA) are 4-6 m during March and 2-4 m during September. The positive bias in the eastern Siberian Sea is still present in the EQUIL run but smaller than in CCSM3. Gent et al. (2010) report an improvement of the annual mean thickness in the CCSM3.5. In the TRANS run the sea ice thickness in the Siberian sector is decreased compared to EQUIL because of the overall background temperature increase. 

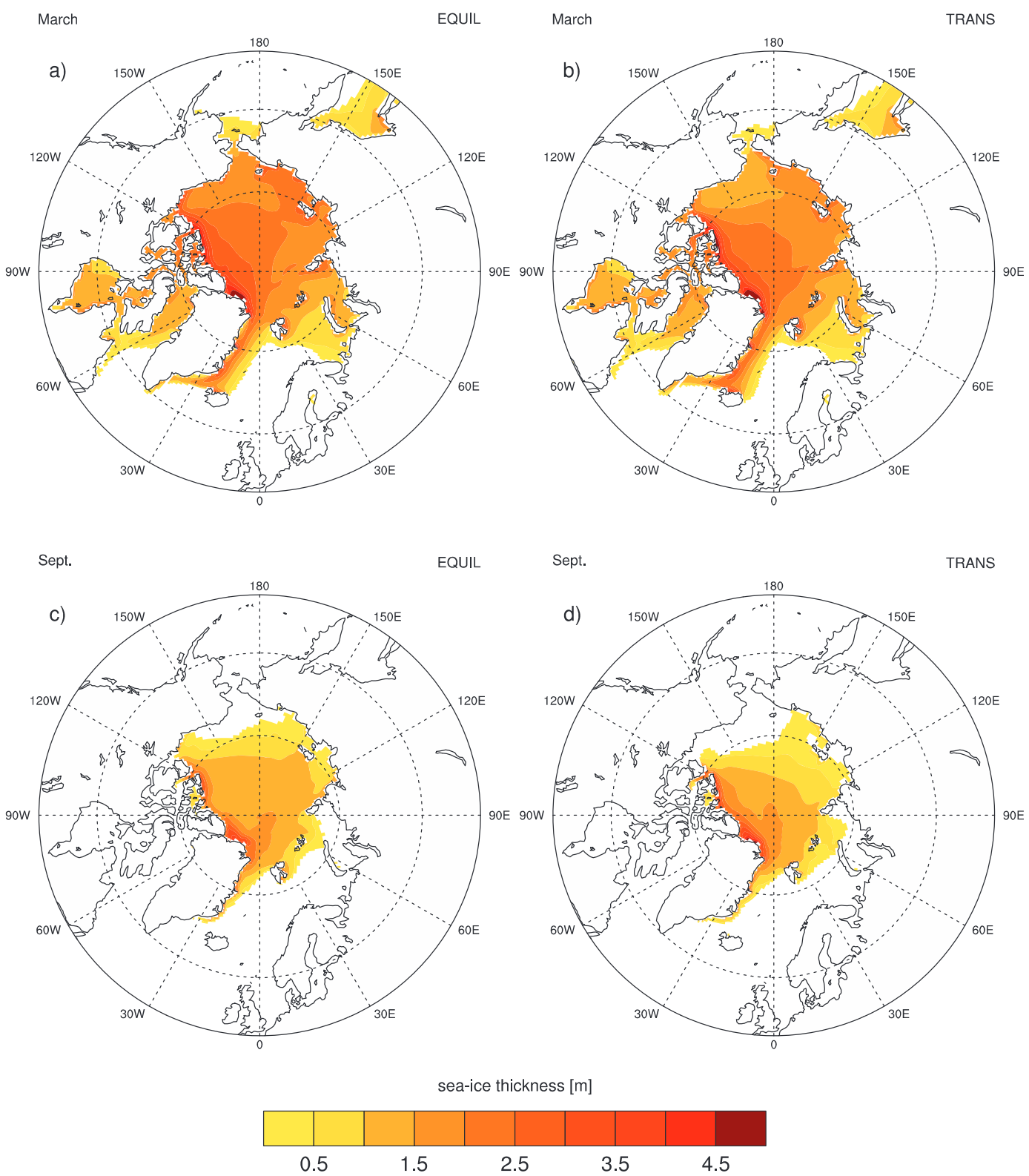

FIG. 1. Climatological sea ice thickness for (a),(b) March and (c),(d) September. The climatology of the (a),(c) EQUIL and (b),(d) TRANS simulations is shown

The spatial pattern of the sea ice area anomaly in both simulations is shown in Fig. 2. It closely resembles the 2005-07 September reduction simulated by a regional climate model and observed from satellite (Kauker et al. 2009, see their Fig. 1). The main reduction in the EQUIL run is located in the Kara and Laptev Seas, while in TRANS the reduction is located more in the Beaufort Sea region (Fig. 2c).

The ensemble mean EQUIL sea ice area during September is $4.4 \times 10^{6} \mathrm{~km}^{2}$ with a standard deviation of $0.6 \times 10^{6} \mathrm{~km}^{2}$ as shown in Fig. 3a. The sea ice cover in
EQUIL-ANOM is reduced to $2.2 \times 10^{6} \mathrm{~km}^{2}$ with a slightly smaller standard deviation $\left(0.5 \times 10^{6} \mathrm{~km}^{2}\right)$. The reduction amounts to $50 \%$. The mean reduction in the TRANS simulation is $52 \%$ (Fig. $3 \mathrm{~b}$ ). The TRANS run has a mean sea ice area of $4.0 \times 10^{6} \mathrm{~km}^{2}(0.5 \times$ $\left.10^{6} \mathrm{~km}^{2}\right)$ and TRANS-ANOM $1.9 \times 10^{6} \mathrm{~km}^{2}(0.3 \times$ $10^{6} \mathrm{~km}^{2}$ ). These reductions are much larger than the observed sea ice reduction of $38 \%$ during September 2007 compared with climatology.

Although the initial reduction of sea ice area is substantial in the perturbed runs the sea ice area recovers to 


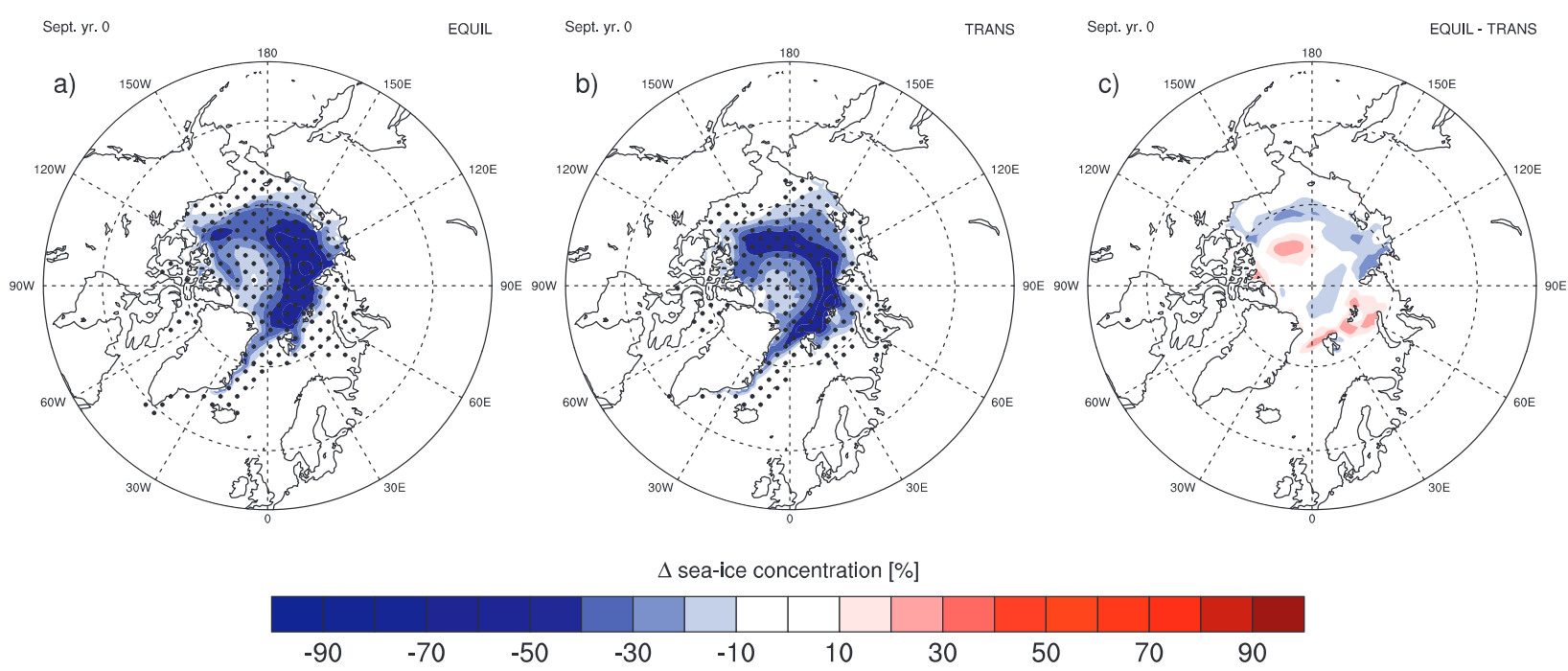

FIG. 2. Ensemble-mean sea ice-concentration change during September of year 0 for the (a) equilibrium and (b) transient runs. (c) Difference of the reduction between the equilibrium and transient simulations. The dots in (a) and (b) indicate the region where the anomalies are significant at the $99 \%$ confidence using a $t$ test.

the unperturbed state after roughly $3 \mathrm{yr}$ as shown in Figs. 3a,b. Similarly, the sea ice thickness rebounds to the unperturbed state in both cases in approximately 5 yr (Figs. 3c,d). Similar recovery times are reported by Schröder and Connolley (2007) and by Tietsche et al. (2011). As can be seen in Fig. 3 there is no difference in the recovery time in the EQUIL and TRANS simulations. This is an interesting fact. In terms of the global recovery time scale the sea ice cover seems to behave similarly in an equilibrium state and in a transient state and independently of the different background $\mathrm{CO}_{2}$ concentrations.

A reduction of sea ice area and thickness usually increases the ice velocity since the ice can flow more freely and crush more easily. However, the mean velocity changes in the Arctic Basin of the ANOM runs are small and are well within the spread of the EQUIL and TRANS runs (not shown). The small changes in average velocity are caused by two regional differences. On one hand, the changes that occur over thick ice have a small impact since the ice can still sustain the pressure. On the other hand, close to the ice edge the remaining ice melts completely and thus will not change the average velocity.

Related to the velocity is the area and volume flux through the straits and openings. The volume flux plays an important role in transporting freshwater to different regions outside the Arctic Ocean. The changes in inflow and outflow through the main connections from the Arctic Ocean to the adjacent basins show the expected patterns after an anomaly, as visible in Figs. 4 and 5. In the Fram Strait the area and volume fluxes are reduced in the ANOM runs during late winter and spring of years 1 and 2 (Figs. 4a,e, 5a,e). This is approximately the time the transpolar drift stream needs to transport ice from the Siberian coast (the location of the sea ice decrease) to the Fram Strait. The throughflow difference to and from the Barents Sea is small (Figs. $4 b, f, 5 b, f$ ). In the Bering Strait the flux into the Arctic Basin during late winter of year 0 is reduced but very small overall (Figs. $4 \mathrm{~d}, \mathrm{~h}, 5 \mathrm{~d}, \mathrm{~h})$. These changes are due to a late formation of sea ice in the Pacific sector. The area flux changes in the CAA are small (Figs. 4c,g, 5c,g). The volume flux on the other hand is decreased in the ANOM runs because of the reduced thickness near the CAA. Note that all the changes are within the range of variability.

\section{b. Ocean}

The ocean with its large inertia is responding quite slowly to the changes induced by the sea ice albedo changes. The total heat content in the Arctic Basin shows no significant changes during and after the anomaly (not shown). This suggests that the change is either of small amplitude or confined to a small region or layer. Indeed, the mean ocean temperature in the Arctic increases by about $0.6^{\circ} \mathrm{C}$ near the surface in the EQUILANOM in year 0 and by $0.8^{\circ} \mathrm{C}$ in the TRANS-ANOM compared with the unperturbed state. The differences are visible only during the summer months since the temperatures return to freezing during the winter months. The anomaly signal is not visible below $200 \mathrm{~m}$.

The mean surface salinity in the Arctic Basin is decreased during the summer of year 0 by about 0.45 psu in EQUIL-ANOM and about 0.35 psu in TRANS-ANOM compared with the unperturbed state (the difference between the TRANS and TRANS-ANOM September 

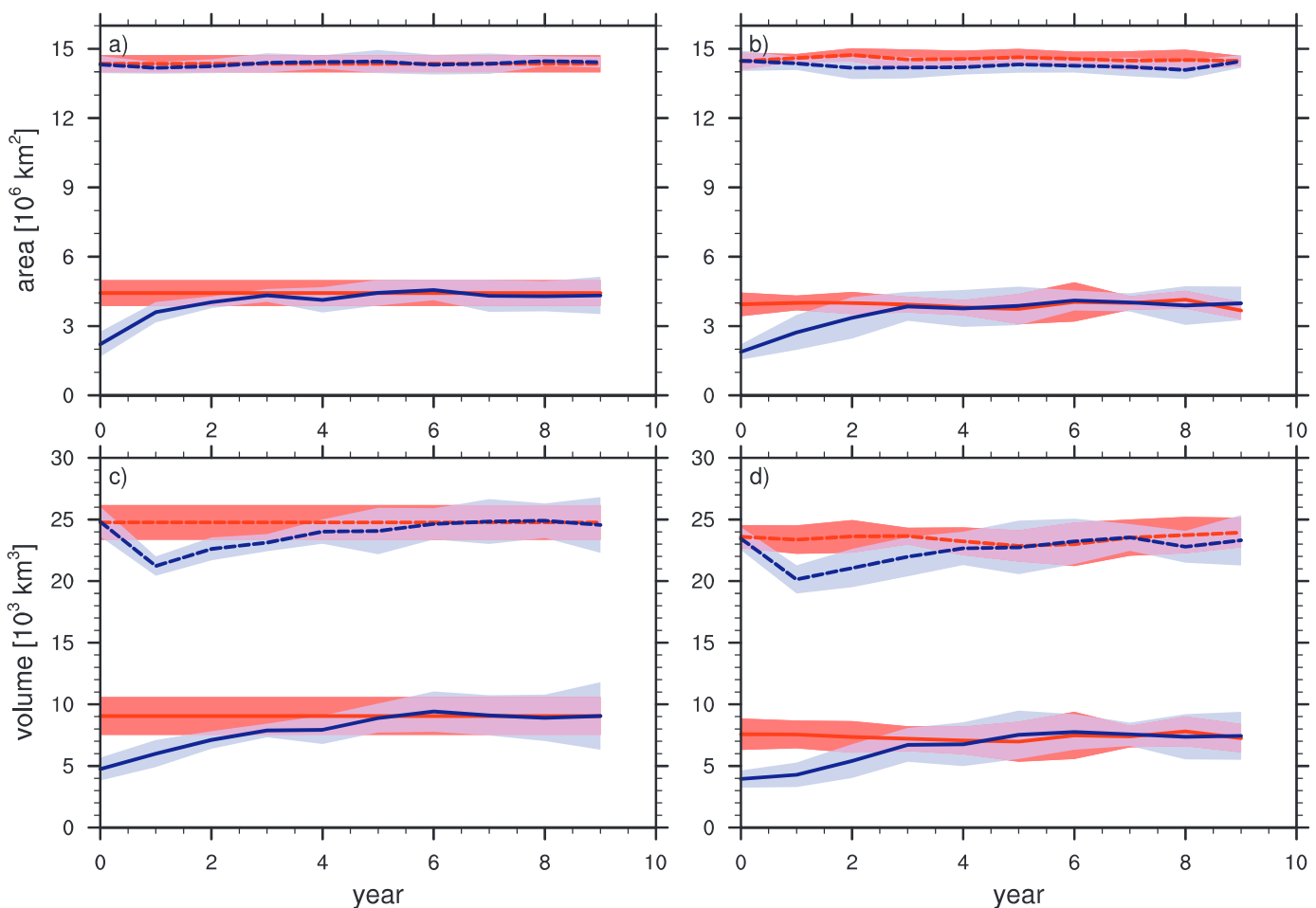

FIG. 3. Time series of sea ice area in (a) the equilibrium case and (b) the transient case, and of sea ice volume in (c) the equilibrium case and (d) the transient case. The solid lines are the September values and the dashed lines are the March values. The red lines denote the unperturbed state and the blue lines are the anomaly simulations. The light color shading denotes one standard deviation.

values is shown in Fig. 6a). The salinity effect also diminishes with increasing depth similar to the temperature. However, there is one distinct difference. While the temperature changes rebound to near zero every winter, the salinity change has a generally upward recovery trend with yearly changes superimposed. Of course this trend reduces with increasing depth and time and disappears below about $200 \mathrm{~m}$.

The spatial salinity differences during September in the uppermost levels show the freshening due to the ice melt in the Arctic Basin (Fig. 6a). However, in some coastal regions the water is saltier. In our experiments melt starts as soon as sunlight hits the sea ice pack and thus sea ice in lower latitudes melts earlier in the perturbed simulations. Indeed, the coastal regions show a freshening from March through June. After that time the majority of the coastal ice is melted. From July onward the perturbed simulations cannot add additional freshwater since the ice is melted. The unperturbed runs still have ice present and thus add freshwater to the ocean. This results in a positive salinity anomaly from July onward. Even though there are some structural differences for the equilibrium and transient simulations, the general picture is similar.
The salinity in the coastal region can be further influenced by changes in the hydrological cycle. Generally, the perturbed runs have slightly more runoff as compared to the unperturbed runs at least for the first few years. This is especially true during the summer months. However, the changes are very patchy and no general conclusions can be drawn in terms of significant changes in salinity.

The changes in salinity (and temperature) trigger a "Great Salinity Anomaly" (GSA) similar to those observed in the past (e.g., Belkin et al. 1998; Belkin 2004). Typically the observed GSAs, once they are at the southern tip of Greenland, take about 7-8 yr to return to the Arctic.

In both simulation sets the salinity and temperature anomaly is produced during the summer of year 0 at the edge of the ice export region just east of Greenland (Fig. 6). The positive salinity anomalies are due to changes in ice advection and melt. In the unperturbed runs the ice emerging from Fram Strait is thicker and has higher concentrations compared to the perturbed runs. Thus the ice will not travel as far along the East Greenland Current in the perturbed runs, resulting in a positive salinity anomaly. In the transient case the positive salt anomaly around southern Greenland almost disappears during the first winter. However, during 

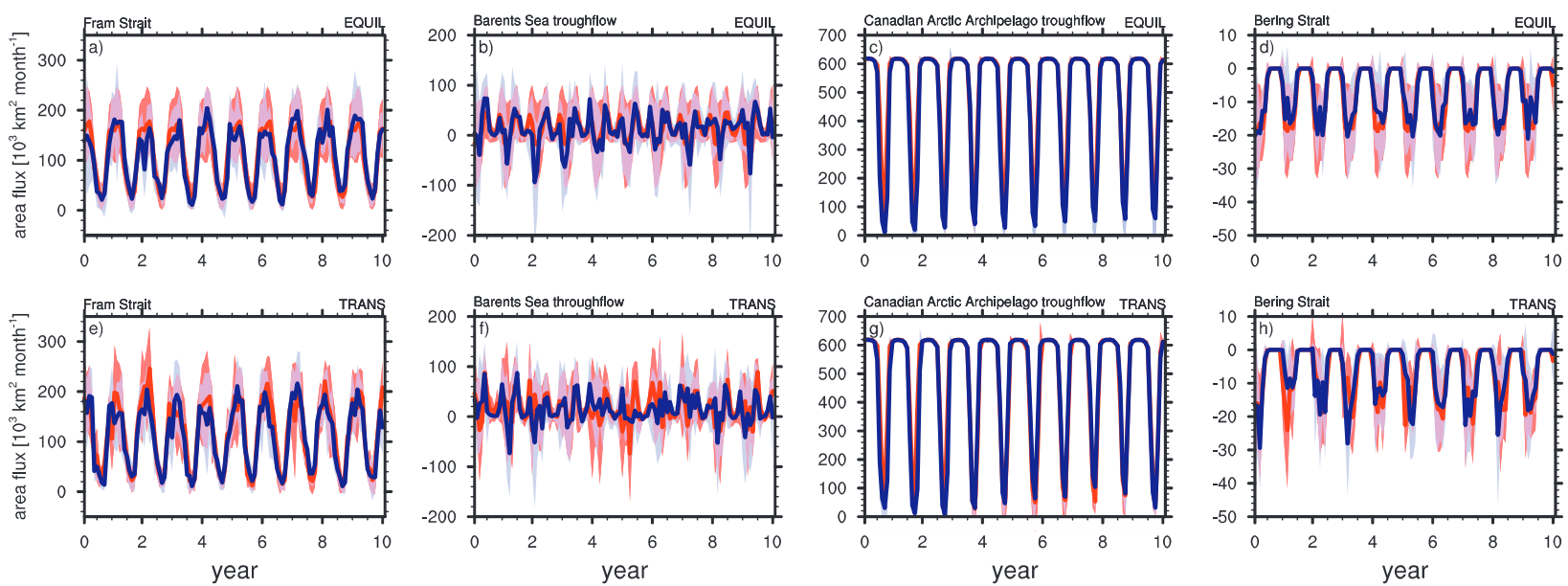

FIG. 4. Area flux through the openings of the Arctic Ocean for the (a)-(d) equilibrium and (e)-(h) transient cases: flux through the (a),(e) Fram Strait, (b),(f) Barents Sea, (c),(g) CAA, and (d),(h) Bering Strait. The red line denotes the unperturbed state and the blue line the perturbed state. The light color shading denotes one standard deviation. Fluxes into the Arctic Basin are negative.

late winter and spring a substantial contribution from the Labrador Sea is feeding the GSA because of the lower volume flux through the CAA. The anomaly is produced at the edge of the sea ice cover. The anomaly reaches the high latitudes again after $8-9$ yr.

In the equilibrium setting the positive salinity anomaly is fed by the East Greenland Current and by a very small part of the Labrador Sea (not shown). As in the transient case the reduced sea ice volume advection is responsible for the anomaly. The anomaly starts to travel around the North Atlantic reaching the high latitudes again after roughly $8-9$ yr. During year 5 the anomaly receives a large salt contribution from the southwestern North Atlantic. This anomaly is related to precipitation changes near the Caribbean Sea and it is questionable whether this anomaly is related directly to the sea ice anomaly.
Several authors have suggested a link between ice exported through the Fram Strait and the meridional overturning circulation on a short time scale (e.g., Mauritzen and Häkkinen 1997; Holland et al. 2001; Mysak et al. 2005). In our experiments the Atlantic meridional overturning circulation shows some variability but no signal that can be linked to the ice export (not shown). The large changes in salinity and temperature remain in the Arctic Basin. The advected changes are small and do not alter substantially the overturning circulation.

\section{c. Atmosphere}

The changes in the atmosphere between the unperturbed state and the anomalies are short-lived and do not show such a persistence and coherence as the changes in the ocean or sea ice. This was also noted by Overland
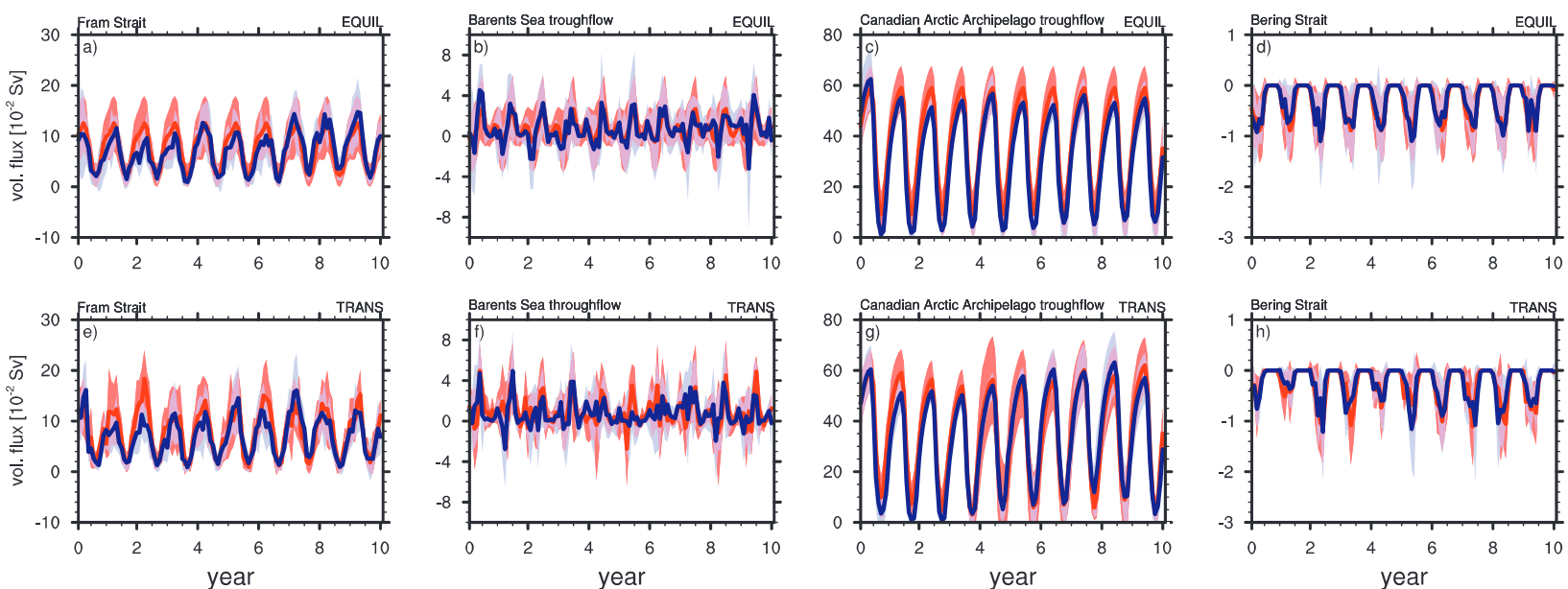

FIG. 5. As in Fig. 4, but for volume flux. 

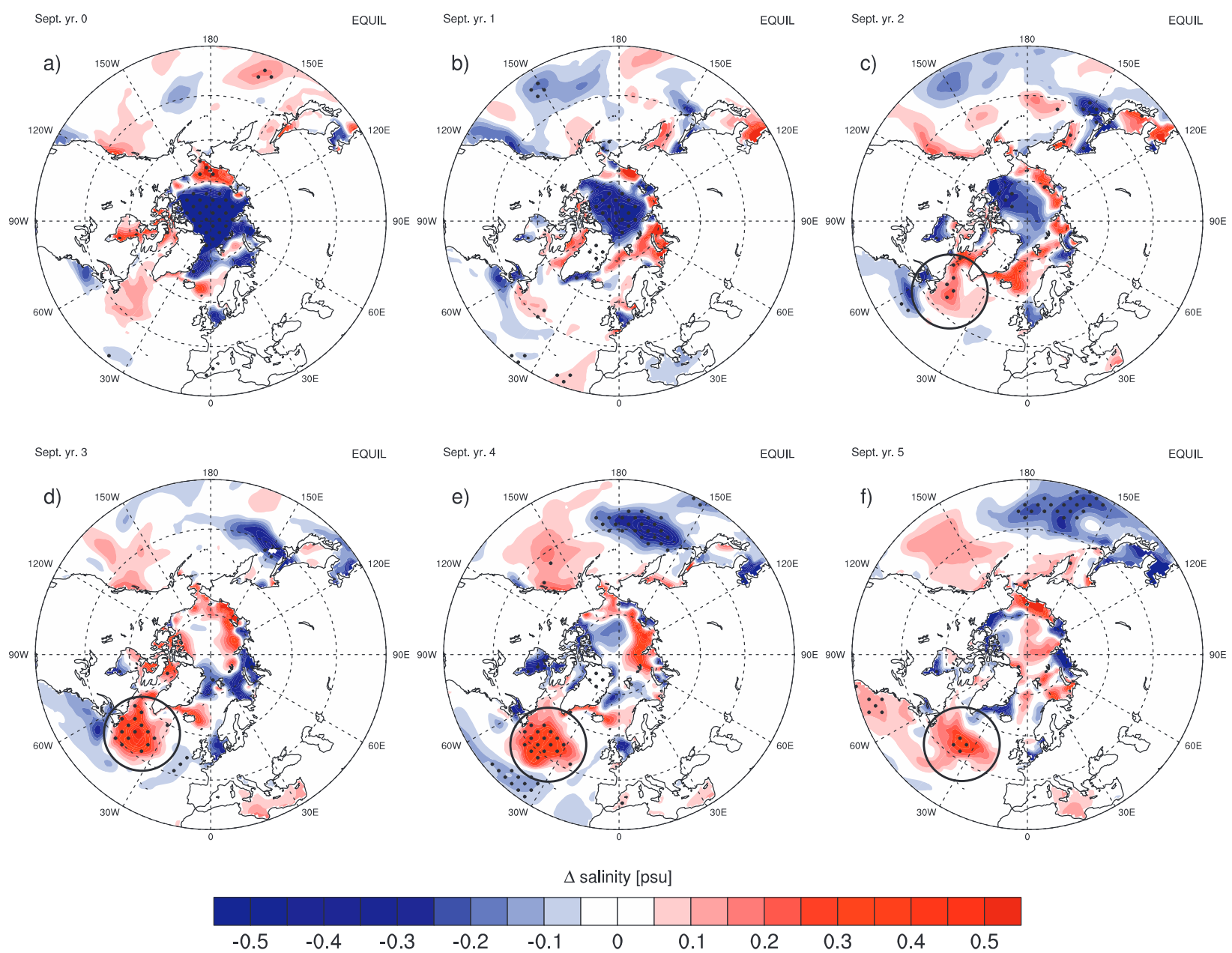

FIG. 6. Ensemble-mean September salinity anomalies from the transient simulations from year (a) 0, (b) 1, (c) 2, (d) 3, (e) 4, and (f) 5 . The dots denote areas where the anomalies are significant at $99 \%$ confidence using a $t$ test. The black circles indicate the position of the GSA. The EQUIL simulation is similar and thus not shown.

and Wang (2010) using observations. In the simulations the largest changes in atmospheric properties are visible during fall and winter. Thus, the main focus is on the fall (October-December; OND) and winter (January-March; JFM) seasons following the initial anomaly (i.e., year 0). As discussed above the amplitude of the sea ice anomaly is similar in the two sets of experiments. However, the location where the sea ice changes occur differs in the two sets of experiments (Fig. 2c).

During the peak of the ice anomaly (i.e., September of year 0) the TRANS-ANOM and EQUIL-ANOM runs show about a $10 \%-20 \%$ increase in total cloud cover in the region of maximum sea ice area loss (not shown). The increase in cloud amount is mainly due to more lowlevel clouds in our model simulations. This is in line with the results from Schweiger et al. (2008) and Vavrus et al. (2010). This anomalous cloud cover is not present during
July and August. In line with the cloud amount, the latent heat fluxes and the SAT are also increased in the ANOM runs. The mean SAT averaged over the sea icefree regions is up to $4^{\circ} \mathrm{C}$ warmer in the ANOM simulations for both the EQUIL and TRANS simulations.

The surface temperature response to sea ice forcing shows some regional differences during both seasons between the equilibrium and transient simulations. During fall the equilibrium simulations show a robust cooling over Europe (Fig. 7a) and a nonrobust cooling over Siberia. Petoukhov and Semenov (2010) show that a sea ice decrease in the Barents and Kara Seas can lead to cold winters over Eurasia. The transient simulation shows a warming over northern Siberia and no cooling signature over Europe (Fig. 7b). During winter the equilibrium runs show almost no SAT anomalies (Fig. 7c). The transient case on the other hand shows a warming over North 

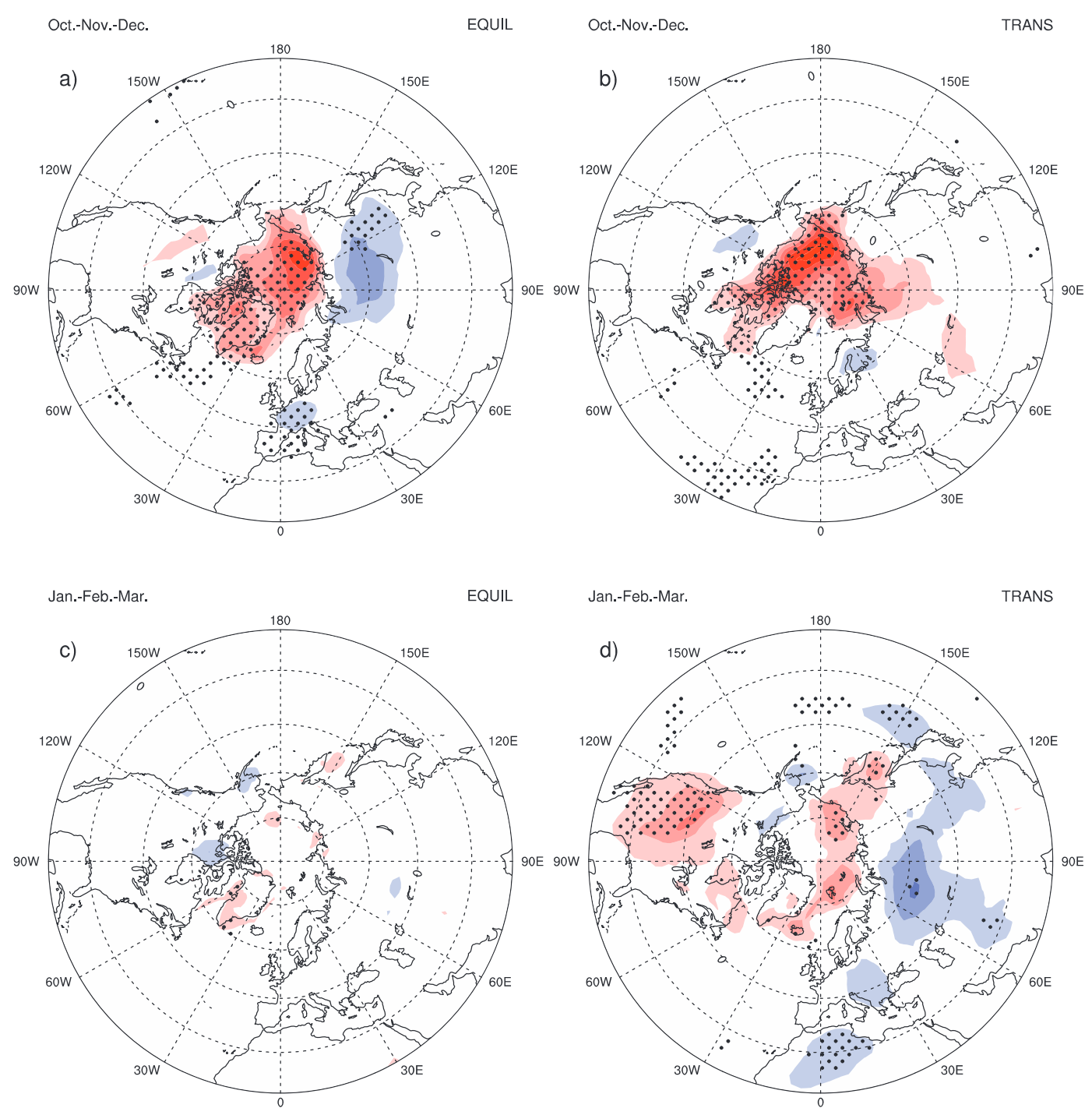

$\triangle \mathrm{SAT}\left[{ }^{\circ} \mathrm{C}\right]$

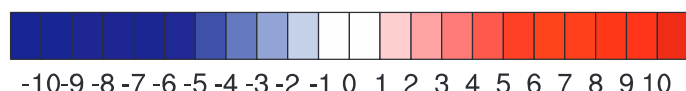

FIG. 7. Ensemble-mean (a),(b) OND and (c),(d) JFM SAT anomalies for the (a),(c) equilibrium and (b),(d) transient simulations. The dots denote areas where the anomalies are significant at $99 \%$ confidence using a $t$ test.

America and the Arctic and a cooling around the Mediterranean and over Siberia (Fig. 7d).

The temperature changes extend throughout the whole tropospheric air column. As a consequence the geopotential height changes accordingly (Figs. 8a,d, 9a,d). Similar results where reported by Overland and Wang (2010) after a large sea ice decrease. The geopotential height changes occur in different locations in the transient and equilibrium runs. In line with the geopotential height changes, the location of the jets and storm tracks change as well.
During fall and winter, a positive geopotential height anomaly at $200 \mathrm{hPa}$ is centered over the polar region and reaches into the extratropics in the equilibrium case (Figs. 8a, 9a), inducing a southward shift of the jets over the eastern North Atlantic and Europe (Figs. 8b, 9b). Accordingly, the North Atlantic Oscillation (NAO) is slightly more negative in the EQUIL-ANOM compared with EQUIL (not shown). A shift toward more negative values of the NAO due to low sea ice cover was reported by Alexander et al. (2004), Deser and Teng (2008), and Francis et al. (2009). 

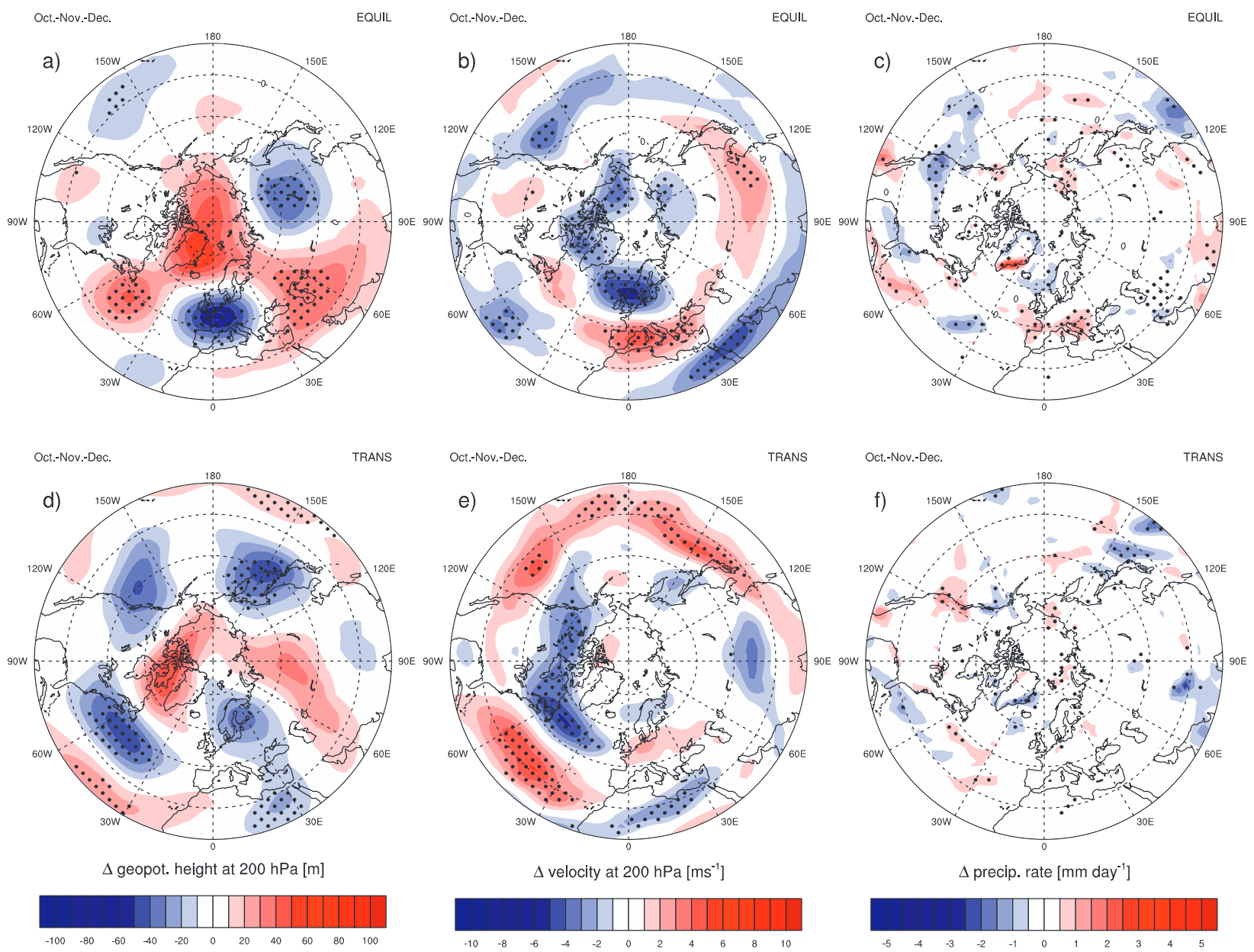

FIG. 8. OND anomaly fields for the (a)-(c) equilibrium state and (d)-(f) transient case: (a),(d) geopotential height changes at $200 \mathrm{hPa}$, (b),(e) velocity changes at $200 \mathrm{hPa}$, and (c),(f) total snow and liquid precipitation changes. The dots denote areas where the anomalies are significant at $99 \%$ confidence using a $t$ test.

In the transient simulations the changes in geopotential height over the western North Atlantic basin are of opposite direction compared with the equilibrium case (Fig. 8d) and are linked to a southward shift of the jet in that region (Fig. 8e). The amplitude of the velocity changes is larger during winter compared with during the fall (cf. Figs. 8e, 9e). The changes of the NAO in the transient case are negligible. In general, our simulations show that in equilibrium the main changes are over the eastern North Atlantic and Europe, while in the transient setting the changes are over the western North Atlantic and eastern North America.

Relating the changes in SAT, geopotential height, and velocity is not so obvious. Honda et al. (2009) suggested a triggering of stationary Rossby wave trains by anomalous low sea ice cover in the Barents and Kara Seas producing temperatures lower than normal over Eurasia.

With our set of experiments we cannot definitively determine the relation between SAT and geopotential height changes, especially since only some changes are robust. While the changes in each experiment are coherent, they differ between the experiments. We will discuss this further in the conclusions section.

Comparing the location of the velocity changes of the unperturbed state in both simulation sets, we find that over the Pacific Ocean the jets intensify and their longitudinal extent is increased in the transient case but not in the equilibrium case. Alexander et al. (2004) showed that sea ice reduction in the Pacific sector, the location of the transient sea ice decrease, intensified the atmospheric circulation in that region. Bhatt et al. (2008) simulated an increase in geopotential height during August over the Bering Sea using the 1995 sea ice area reduction. In our simulations we see indeed an increased geopotential height in that region during August (not shown). However, the peak change is located more toward the pole compared to Bhatt et al. (2008).

Precipitation changes are mostly driven by changes in large-scale atmospheric patterns (Figs. 8c,f, 9c,f) and 

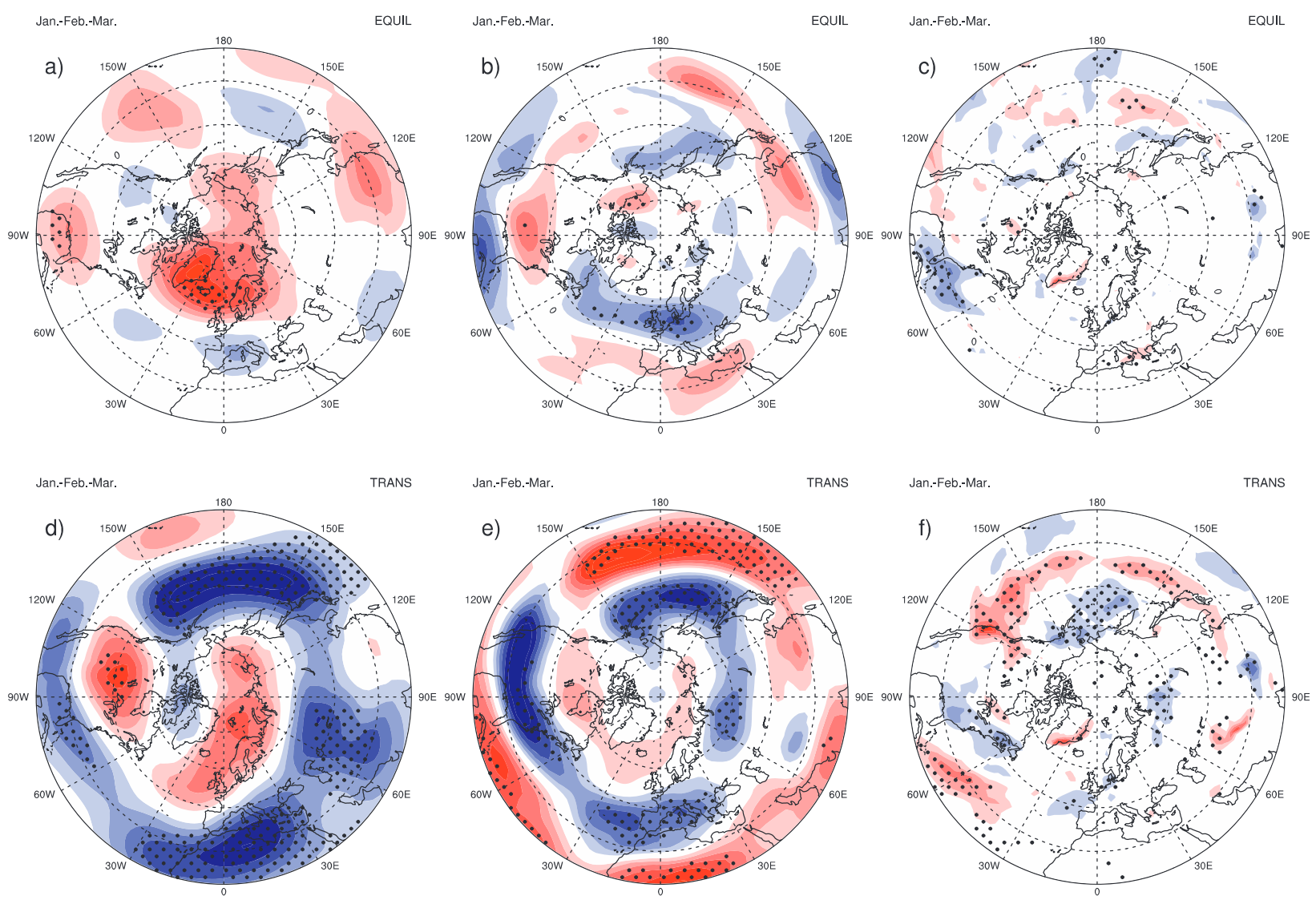

$\Delta$ geopot. height at $200 \mathrm{hPa}[\mathrm{m}]$
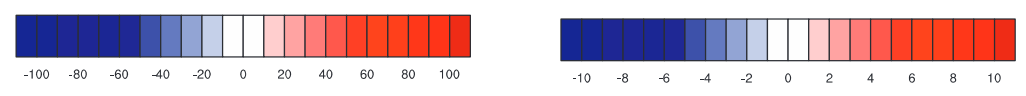

$\Delta$ precip. rate $\left[\mathrm{mm}\right.$ day $\left.^{-1}\right]$

FIG. 9. As in Fig. 8, but for JFM.

follow the latitudinal changes of the storm tracks. In some regions the changes are robust although small compared to the total precipitation. Also some orographic effects are visible, for example, in western North America or Greenland. During autumn and winter the precipitation decreases in the equilibrium simulations between $20^{\circ}$ and $90^{\circ} \mathrm{N}$. On the other hand, in the transient runs the precipitation increases during both seasons. Francis et al. (2009) report a nonsignificant precipitation increase in the Northern Hemisphere during winters following low sea ice cover. In our simulations the total hemispheric changes in precipitation are smaller than $2 \%$ of the total amount.

\section{Conclusions}

In this study we investigate the response of atmosphere and ocean properties to a reduced sea ice cover in the CCSM3.5 climate model. We produce equilibrium and transient ensembles with a negative sea ice anomaly triggered through an albedo reduction. In both settings, the sea ice area is reduced by about $50 \%$ at the end of the first melt season as compared to the unperturbed states. The sea ice area and thickness recover after 3 and $5 \mathrm{yr}$, respectively.

The decreased salinity due to changes in salt rejection and ice melt and the increased temperature due to more open water are visible to a depth of $200 \mathrm{~m}$ in the Arctic Basin. The decreased sea ice transport to the North Atlantic triggers a Great Salinity Anomaly, independent of the background state. In about 8-9 yr the anomaly travels across the North Atlantic Ocean and back to higher latitudes in both simulations. The changes in salinity in the Pacific Ocean are most likely not linked directly to the sea ice anomaly, but rather to atmospheric circulation and precipitation changes.

While in the ocean the response to the sea ice anomaly is similar in the equilibrium and transient cases, in the atmosphere it is not. No robust and coherent anomaly patterns are present in the different simulations and seasons. The precipitation changes are robust in some regions 
and also orographic precipitation effects are visible. However, the changes account for less than $2 \%$ of the total Northern Hemisphere precipitation.

We propose that for the dynamical atmospheric fields the location of the sea ice anomaly and thus the location of the surface air warming are important. In the equilibrium setting the sea ice area changes are located more toward the Kara and Laptev Seas, while in the transient simulations the anomalies are located over the Beaufort Sea.

Changes in geopotential height over the Arctic affect the jet, and hence the storm tracks over North America, the North Atlantic, and Eurasia are shifted. In EQUILANOM a southward shift is visible over the eastern North Atlantic and Europe compared with EQUIL. In TRANS-ANOM a southward shift occurs over the western North Atlantic and eastern North America. Over the Pacific Ocean the location of the storm tracks is not affected. However, the strength and the longitudinal extent changes at least in the transient simulations. This is in agreement with present-day jet variability (Eichelberger and Hartmann 2007). Our results are also in line with the findings of Strey et al. (2010) that the response over the Arctic Basin is thermodynamic and the induced dynamical changes produce the anomalies in the lower latitudes.

However, to verify our hypothesis of a significant sensitivity of the atmospheric response to regional differences in the sea ice change, more work is needed. Several open questions remain about the atmospheric anomalies. It is possible that the changes are due to different initial conditions. It is also unclear whether the differences arise because of the different behavior of a transient versus equilibrium state. Further, it might be that the response is dependent on the background state, that is, the same forcing leads to different changes. Since the albedo anomaly is applied over $1 \mathrm{yr}$, changes are produced before the actual sea ice area minimum and thus no proper relation between sea ice area and atmospheric properties is possible.

As mentioned in the introduction the observed sea ice area and thickness decreased steadily (Maslanik et al. 2007; Nghiem et al. 2007; Serreze et al. 2007; Comiso et al. 2008). Our experimental setup does not create such a decrease. Therefore, a direct comparison with observations has to be made with care.

Some scientists and media speculated that the recent sea ice reduction could be an early warning or a threshold for rapid sea ice loss (e.g., Lindsay and Zhang 2005; Winton 2006). Despite the open questions, we conclude that no rapid nonlinear sea ice loss is likely to occur after a 1-yr reduction of sea ice area. These results are similar to sea ice recovery studies done in the past few years (e.g., Schröder and Connolley 2007; Notz 2009; Tietsche et al.
2011). Thus, a linear extrapolation of a short-lived reduction of sea ice is very unlikely to be useful.

Acknowledgments. We thank the anonymous reviewers and the editor, M. Alexander, for their comments and suggestions.

\section{REFERENCES}

Alexander, M. A., U. S. Bhatt, J. E. Walsh, M. S. Timlin, J. S Miller, and J. D. Scott, 2004: The atmospheric response to realistic Arctic sea ice anomalies in an AGCM during winter. J. Climate, 17, 890-905.

Belkin, I. M., 2004: Propagation of the "Great Salinity Anomaly" of the 1990s around the northern North Atlantic. Geophys. Res. Lett., 31, L08306, doi:10.1029/2003GL019334.

, S. Levitus, J. Antonov, and S.-A. Malmberg, 1998: "Great Salinity Anomalies" in the North Atlantic. Prog. Oceanogr., 41 (1), 1-68, doi:10.1016/S0079-6611(98)00015-9; Corrigendum, 45, 107-108.

Bhatt, U. S., M. A. Alexander, C. Deser, J. E. Walsh, J. S. Miller, M. S. Timlin, J. Scott, and R. A. Tomas, 2008: Arctic sea ice decline: Observations, mechanisms, and implications. The Atmospheric Response to Realistic Reduced Summer Arctic Sea Ice Anomalies, Geophys. Monogr., Vol. 180, Amer. Geophys. Union, 91-110.

Bitz, C. M., P. R. Gent, R. A. Woodgate, M. M. Holland, and $R$. Lindsay, 2006: The influence of sea ice on ocean heat uptake in response to increasing $\mathrm{CO}_{2}$. J. Climate, 19, 2437-2450.

Boé, J., A. Hall, and X. Qu, 2009: September sea-ice cover in the Arctic Ocean projected to vanish by 2100. Nat. Geosci., 2, 341343, doi:10.1038/ngeo467.

Bourke, R. H., and R. P. Garrett, 1987: Sea ice thickness distribution in the Arctic Ocean. Cold Reg. Sci. Technol., 13, 259-280.

Collins, W. D., and Coauthors, 2006: The Community Climate System Model version 3 (CCSM3). J. Climate, 19, 2122-2143.

Comiso, J. C., C. L. Parkinson, R. Gersten, and L. Stock, 2008: Accelerated decline in the Arctic sea ice cover. Geophys. Res. Lett., 35, L01703, doi:10.1029/2007GL031972.

Deser, C., and H. Teng, 2008: Evolution of Arctic sea ice concentration trends and the role of atmospheric circulation forcing, 1979-2007. Geophys. Res. Lett., 35, L02504, doi:10.1029/ 2007 GL032023.

DeWeaver, E. T., and C. M. Bitz, 2006: Atmospheric circulation and its effect on Arctic sea ice in CCSM3 simulations at medium and high resolution. J. Climate, 19, 2415-2436.

Eichelberger, S. J., and D. L. Hartmann, 2007: Zonal jet structure and the leading mode of variability. J. Climate, 20, 5149-5163.

Francis, J. A., W. Chan, D. J. Leathers, J. R. Miller, and D. E. Veron, 2009: Winter Northern Hemisphere weather patterns remember summer Arctic sea-ice extent. Geophys. Res. Lett., 36, L07503, doi:10.1029/2009GL037274.

Gent, P. R., S. G. Yeager, R. B. Neale, S. Levis, and D. A. Bailey, 2010: Improvements in a half degree atmosphere/land version of the CCSM. Climate Dyn., 34, 819-833.

Giles, K. A., S. W. Laxon, and A. L. Ridout, 2008: Circumpolar thinning of Arctic sea ice following the 2007 record ice extent minimum. Geophys. Res. Lett., 35, L22502, doi:10.1029/ 2008GL035710.

Holland, M. M., C. M. Bitz, M. Eby, and A. J. Weaver, 2001: The role of ice-ocean interactions in the variability of the North Atlantic thermohaline circulation. J. Climate, 14, 656-675. 
, and B. Tremblay, 2006: Future abrupt reductions in the summer Arctic sea ice. Geophys. Res. Lett., 33, L23503, doi:10.1029/2006GL028024.

Honda, M., J. Inoue, and S. Yamane, 2009: Influence of low Arctic sea-ice minima on anomalously cold Eurasian winters. Geophys. Res. Lett., 36, L08707, doi:10.1029/2008GL037079.

Kalnay, E., and Coauthors, 1996: The NCEP/NCAR 40-Year Reanalysis Project. Bull. Amer. Meteor. Soc., 77, 437-471.

Kauker, F., T. Kaminski, M. Karcher, R. Giering, R. Gerdes, and M. Vossbeck, 2009: Adjoint analysis of the 2007 all time Arctic sea-ice minimum. Geophys. Res. Lett., 36, L03707, doi:10.1029/ 2008 GL036323.

Kay, J. E., and A. Gettelman, 2009: Cloud influence on and response to seasonal Arctic sea ice loss. J. Geophys. Res., 114, D18204, doi:10.1029/2009JD011773.

Kwok, R., G. F. Cunningham, M. Wensnahan, I. Rigor, H. J. Zwally, and D. Yi, 2009: Thinning and volume loss of the Arctic Ocean sea ice cover: 2003-2008. J. Geophys. Res., 114, C07005, doi:10.1029/2009JC005312.

Laxon, S., N. Peacock, and D. Smith, 2003: High interannual variability of sea ice thickness in the Arctic region. Nature, 425, 947-950, doi:10.1038/nature02050.

Lindsay, R. W., and J. Zhang, 2005: The thinning of Arctic sea ice, 1988-2003: Have we passed a tipping point? J. Climate, 18, 4879-4894.

,-- A. Schweiger, M. Steele, and H. Stern, 2009: Arctic sea ice retreat in 2007 follows thinning trend. J. Climate, 22, 165-176.

Liu, Y., J. R. Key, and X. Wang, 2009: Influence of changes in sea ice concentration and cloud cover on recent Arctic surface temperature trends. Geophys. Res. Lett., 36, L20710, doi:10.1029/ 2009GL040708

Maslanik, J. A., C. Fowler, J. Stroeve, S. Drobot, J. Zwally, D. Yi, and W. Emery, 2007: A younger, thinner arctic ice cover: Increased potential for rapid, extensive sea-ice loss. Geophys. Res. Lett., 34, L24501, doi:10.1029/2007GL032043.

Mauritzen, C., and S. Häkkinen, 1997: Influence of sea ice on the thermohaline circulation in the Arctic-North Atlantic Ocean. Geophys. Res. Lett., 24, 3257-3260.

Mysak, L. A., K. Wright, J. Sedláček, and M. Eby, 2005: Simulation of sea ice and ocean variability in the Arctic during 1955-2002 with an Intermediate Complexity Model. Atmos.-Ocean, 43 (1), 101-118, doi:10.3137/ao.430106.

Nghiem, S. V., I. G. Rigor, D. K. Perovich, P. Clemente-Colón, J. W. Weatherly, and G. Neumann, 2007: Rapid reduction of Arctic perennial sea ice. Geophys. Res. Lett., 34, L19504, doi:10.1029/2007GL031138.

Notz, D., 2009: The future of ice sheets and sea ice: Between reversible retreat and unstoppable loss. Proc. Natl. Acad. Sci. USA, 106, 20 590-20 595.

Overland, J., and M. Wang, 2010: Large-scale atmospheric circulation changes are associated with the recent loss of Arctic sea ice. Tellus, 62A (1), 1-9, doi:10.1111/j.1600-0870.2009.00421.x.
- J. Turner, J. Francis, N. Gillett, G. Marshall, and M. Tjernström, 2008: The Arctic and Antarctic: Two faces of climate change. Eos, Trans. Amer. Geophys. Union, 89 (19), 177-178.

Petoukhov, V., and V. A. Semenov, 2010: A link between reduced Barents-Kara sea ice and cold winter extremes over northern continents. J. Geophys. Res., 115, D21111, doi:10.1029/ 2009JD013568.

Schröder, D., and W. M. Connolley, 2007: Impact of instantaneous sea ice removal in a coupled general circulation model. Geophys. Res. Lett., 34, L14502, doi:10.1029/2007GL030253.

Schweiger, A. J., J. Zhang, R. W. Lindsay, and M. Steele, 2008: Did unusually sunny skies help drive the record sea ice minimum of 2007? Geophys. Res. Lett., 35, L10503, doi:10.1029/ 2008GL033463.

Serreze, M. C., M. M. Holland, and J. Stroeve, 2007: Perspectives on the Arctic's shrinking sea-ice cover. Science, 315, 1533 1536, doi:10.1126/science.1139426.

Simmonds, I., and K. Keay, 2009: Extraordinary September Arctic sea ice reductions and their relationships with storm behavior over 1979-2008. Geophys. Res. Lett., 36, L19715, doi:10.1029/ 2009GL039810.

Solomon, S., D. Qin, M. Manning, M. Marquis, K. Averyt, M. M. B Tignor, H. L. Miller Jr., and Z. Chen, Eds., 2007: Climate Change 2007: The Physical Sciences Basis. Cambridge University Press, $996 \mathrm{pp}$.

Strey, S., W. Chapman, and J. Walsh, 2010: The 2007 sea ice minimum: Impacts on the Northern Hemisphere atmosphere in late autumn and early winter. J. Geophys. Res., 115, D23103, doi:10.1029/2009JD013294.

Stroeve, J., M. M. Holland, W. Meier, T. Scambos, and M. Serreze, 2007: Arctic sea ice decline: Faster than forecast. Geophys. Res. Lett., 34, L09501, doi:10.1029/2007GL029703.

, M. Serreze, S. Drobot, S. Gearheard, M. M. Holland, J. Maslanik, W. Meier, and T. Scambos, 2008: Arctic sea ice extent plummets in 2007. Eos, Trans. Amer. Geophys. Union, 89 (2), 13-14.

Tietsche, S., D. Notz, J. H. Jungclaus, and J. Marotzke, 2011: Recovery mechanisms of Arctic summer sea ice. Geophys. Res. Lett., 38, L02707, doi:10.1029/2010GL045698.

Våge, K., and Coauthors, 2009: Surprising return of deep convection to the subpolar North Atlantic Ocean in winter $2007-$ 2008. Nat. Geosci., 2, 67-72, doi:10.1038/ngeo382.

Vavrus, S., M. M. Holland, and D. A. Bailey, 2010: Changes in Arctic clouds during intervals of rapid sea ice loss. Climate Dyn., 36, 1475-1489.

Winton, M., 2006: Does the Arctic sea ice have a tipping point? Geophys. Res. Lett., 33, L23504, doi:10.1029/2006GL028017.

Zhang, J., M. Steele, R. Lindsay, A. Schweiger, and J. Morison, 2008: Ensemble 1-year predictions of Arctic sea ice for the spring and summer of 2008. Geophys. Res. Lett., 35, L08502, doi:10.1029/2008GL033244 